\title{
Multiple organ dysfunction in children admitted at pediatric intensive care unit of the Children Hospital, Multan.
}

\footnotetext{
1. MBBS

Post Graduate Registrar Paediatrics Medicine

The Children's Hospital and ICH, Multan.

2. MBBS, FCPS (Paediatrics Medicine) Associate Professor

The Children's Hospital \& ICH, Multan.

3. MBBS, FCPS (Paediatrics Medicine) Assistant Professor Paediatrics Medicine,

The Children's Hospital and ICH Multan.
}

Correspondence Address:

Dr. Asim Khurshid

Department of Paediatrics Medicine

The Children's Hospital and ICH,

Multan.

asimkhurshiddr@gmail.com

Article received on:

20/02/2019

Accepted for publication:

$13 / 04 / 2020$

\section{INTRODUCTION}

Earlier described as "multiple system organ failure", the term "multiple organ dysfunction syndrome (MODS)" was initially explained in the 1960s as bleeding, respiratory failure as well as sepsis. ${ }^{1,2}$ MODS is defined as ${ }^{3}$ "the development of potentially reversible physiologic derangement involving two or more organ systems not involved in the disorder that resulted in ICU admission, and arising in the wake of a potentially life threatening physiologic insult." Quite a few predisposing factors are described to be linked with MODS but shock because of any cause, sepsis and tissue hypoperfusion are most commonly witnessed. ${ }^{4}$ A substandard immune response or immune paralysis is considered to played a major role in the development of MOD.

MODS is frequently witnessed in the PUCUs, causing significant amount of mortality. ${ }^{5}$ Pathophysiology of MODS involves a severe, systemic as well as uncontrolled inflammatory process that progress in to MODS. ${ }^{6}$ Experts advise early diagnosis of MODS when there is dysfunction of at least 2 organs or systems. ${ }^{7,8}$ Diagnostic criteria for MODS have been changing over time and no set criteria are endorsed for the diagnosis of organ dysfunction. In 1986, Wilinson $\mathrm{JD}$ and Coworkers were the earliest to describe the diagnostic criteria for diagnosing MOD whereas they reported incidence of MOD as $27 \%$ in admitted cases in the PICU. In Pakistan, not much work is seen about MODS and its impact among children. ${ }^{9} \mathrm{~A}$ study done by Haque $\mathrm{A}$ et al from Karachi ${ }^{10}$ noted prevalence of MOD as $25.2 \%$ over a span of 2 years A study from Cairo, Egypt $^{4}$ noted a high prevalence of MOD as $72 \%$ on $1^{\text {st }}$ day of admission in the PICU.

The aim of this study was to document the proportion of multiple organ dysfunction in children admitted to PICU. There is scarcity of data at national as well as international level 
while not much work is seen in Pakistan on this. The results of this study will generate baseline database of our local population and ascertain current magnitude of the problem.

\section{MATERIAL \& METHODS}

A Case series, conducted at the department of Pediatric Medicine, The Children's hospital and the Institute of Child Health, Multan, from May to November 2019. Approval from Institutional Ethical Committee was taken for this study. Informed consent was seeked from parents/ guardians of all study participants.

A sample size of 101 was calculated by WHO calculator for sample size, by taking $21.4 \%{ }^{11}$ of multiple organ dysfunction in PICU, with level of confidence as $95 \%$ and margin of error as $8 \%$. Non probability consecutive sampling technique was employed. A total of 101 children of both genders, aged 1 month to 15 years, who were critically ill and admitted to PICU irrespective of presenting complaint, with duration of hospitalization more than 24 hours. All cases admitted to PICU following surgical procedures and trauma or patients whose parents did not give consent for participation were excluded.

Variables recorded for each case included name, age, gender, residential status, maternal education, height, weight and BMI. Venous blood sample was taken and sent to the hospital laboratory for baseline investigations to diagnose multiple organ dysfunction after every 24 hours. MOD was defined as $>2$ organ dysfunctions as per criteria defined in Table-I. ${ }^{12}$

Data was analyzed using SPSS version 23.0. Frequency and percentage were calculated for gender, multiple organ dysfunction, residential status and mother's educational level. Mean and standard deviations was calculated for numerical data including age of patients, BMI and duration of PICU stay. Stratification was done with respect to age, gender, residential status, duration of PICU stay and mother's educational level. Post stratification chi square test was applied. $P$ value less than 0.05 was considered significant.

\section{RESULTS}

Out of 101 study cases, 61 (60.4\%) were male whereas 40 (39.6\%) were female. Overall, mean age was $3.62 \pm 1.95$ years while mean age of the male patients was $3.84 \pm 2.16$ years and 3.30 \pm 1.57 years for female $(p=0.180)$. Majority, 85 $(84.2 \%)$ were $<5$ years of age. There were 51 (50.5\%) patients from rural areas and 50 (49.5\%) from urban areas. There were $27(26.7 \%)$ patients who belonged to poor families and 74 (73.3\%) were from middle income families. Seventy two (71.3\%) mothers were illiterate while 29 (28.7\%) were literate.

Overall, mean body mass index (BMI) was 24.85 $\pm 2.20 \mathrm{~kg} / \mathrm{m}^{2}$ while obesity noted in $12(11.9 \%)$ patients. Mean duration of PICU stay was 4.31 \pm 3.39day and 69 (68.3\%) had duration of PICU stay as less than 5 days.

It was observed that MODS was found to be significantly associated with male gender, residential status as rural, maternal education status as illiterate, obesity and duration of PICU as more than 5 days. (Table-II.)

\section{DISCUSSION}

Understanding of the epidemiology as well as outcome of MODS in children is limited because of irregular diagnostic criteria and population's characteristics. Some patients develop additional organ dysfunction during and/or after the first week of PICU admission. These patients might be best categorized as having "progressive MODS," a recently proposed term that will subsequently be discussed later in sections on $\mathrm{New}$ and Progressive MODS. ${ }^{13,14}$

In the present study, 61 (60.4\%) patients were male. Haque $A$ et $\mathrm{al}^{15}$ in a local study found $66.5 \%$ of their cases admitted to PICU as male. Another local study ${ }^{10}$ also documented $66 \%$ male cases which is quite similar to what we noted. El Hamshary AA et al from Cairo, Egypt ${ }^{4}$ noted $70.1 \%$ of the cases with MODS to be male. 


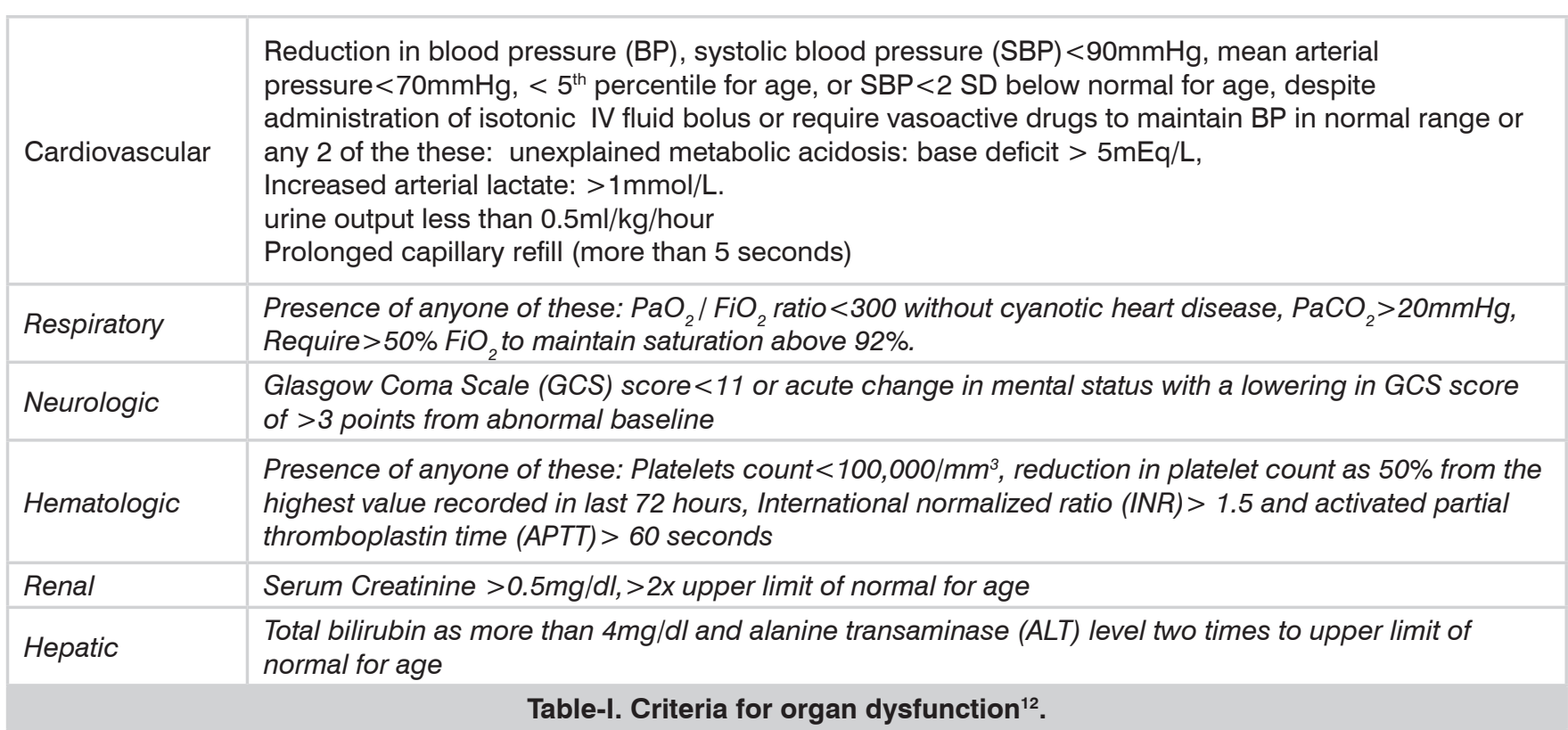

\begin{tabular}{|c|c|c|c|c|}
\hline & & \multicolumn{2}{|c|}{ Multiple Organ Dysfunction } & \multirow[b]{2}{*}{ P-Value } \\
\hline \multicolumn{2}{|c|}{ Study Variables } & Yes & No & \\
\hline Gender & Female & $08(24.2 \%)$ & $32(41.1 \%)$ & 0.032 \\
\hline Age & $<5$ Years & $31(93.9 \%)$ & $54(79.4 \%)$ & 0.082 \\
\hline \multirow{2}{*}{ Residential Status } & Rural & $23(69.7 \%)$ & $28(41.2 \%)$ & \multirow{2}{*}{0.011} \\
\hline & Urban & $10(30.3 \%)$ & $40(58.8 \%)$ & \\
\hline \multirow{2}{*}{ Socioeconomic Status } & Poor & $11(33.3 \%)$ & $16(23.5 \%)$ & \multirow{2}{*}{0.341} \\
\hline & Middle Income & $22(66.7 \%)$ & $52(76.5 \%)$ & \\
\hline Obesity & No & $33(100 \%)$ & $56(82.4 \%)$ & 0.008 \\
\hline \multirow{2}{*}{ Duration of PICU Stay } & $<5$ days & $13(39.4 \%)$ & $56(82.4 \%)$ & \multirow{2}{*}{$<0.001$} \\
\hline & $>5$ days & $20(60.6 \%)$ & $12(17.6 \%)$ & \\
\hline
\end{tabular}

Overall, mean age was found to be $3.62 \pm 1.95$ years (ranging from 1 year to 8 years) while we noted that most of the patients, 85 (84.2\%) $<5$ years of age. A study from Karachi ${ }^{15}$ also observed mean of the children admitted to PICU as $56.3 \pm 5.5$ months which are pretty similar to what was found in the present research. Another study from Karachi ${ }^{10}$ showed that $63 \%$ cases were aged below 5 years. A study from Egypt ${ }^{4}$ noted $87 \%$ of the children in PICU to be of less than 5 years of age. Giri $A$ and Colleagues from $\mathrm{Nepal}^{5}$ also found $61.2 \%$ of the patients to be less than 5 years of age.

In the present study, 51 (50.5\%) belonged to rural areas and $50(49.5 \%)$ belonged to urban areas. Of these 101 study cases, $27(26.7 \%)$ belonged to poor families and $74(73.3 \%)$ were from middle income families. Sixty nine (68.3\%) mothers were illiterate while 32 (31.7\%) were literate. Ramzan 
$\mathrm{S}$ and Coworkers ${ }^{16}$ found $28 \%$ poverty rate and $40.7 \%$ illiteracy among cases admitted in PICU which is quite similar to us.

Mean duration of PICU stay was $4.31 \pm 3.39$ day and $69(68.3 \%)$ had duration less than 5 days. Ahmad $\mathrm{K}$ and Colleagues noted a similar finding where mean duration of hospital stay in the PICU was 3.89 days. Volakli $E$ et al ${ }^{18}$ found that to be $8.85 \pm 23.28$ days. Ramzan $S$ et $\mathrm{al}^{16}$ also reported similar results.

Multiple Organ Dysfunction was noted in 33 $(32.7 \%)$ patients in the present study. Villeneuve A et $\mathrm{al}^{11}$ reported $21.4 \%$ multiple organ dysfunction in PICU. Ramzan S and Colleagues ${ }^{16}$ also reported $26.7 \%$ MOD. A recent study from Nepal ${ }^{5}$ found MODS to be presented in $51 \%$ of the cases admitted in the PICU.

This is the $1^{\text {st }}$ study done in our region to find out the burden and characteristics of pediatric population suffering with MODS. One of the main limitations of this research was that we did not note any kind of short or long-term outcomes of MODS in affected children. Finding outcomes of MODS among pediatric population in the future studies will further enlighten us about identification of prospects for improvement in the handling and recovery plans focusing improvement of these children.

\section{CONCLUSION}

High Frequency of MOD was observed among children admitted to PICU. Multiple organ dysfunction was found to have association with gender, residential status, obesity, maternal education and prolonged duration of PICU stay. All clinicians treating such patients should anticipate MODS in critically ill children for early diagnosis followed by proper treatment to decrease morbidity and mortality.

\section{Copyright $\odot 13$ Apr, 2020.}

\section{REFERENCES}

1. Feng G, Luo Q, Guo E, Yao Y, Yang F, Zhang B, et al. Multiple organ dysfunction syndrome, an unusual complication of heroin intoxication: A case report and review of literature. Int J ClinExpPathol. 2015 Sep $1 ; 8(9): 11826-30$.
2. Papia G, Dhar P. Multiorgan dysfunction syndrome in the surgical patient. In: The surgical critical care handbook. World Scientific 2016:469-89.

3. Ramírez M. Multiple organ dysfunction syndrome. Curr Probl Pediatr Adolesc Health Care. 2013; 43(10):273-7.

4. El Hamshary AA, El Sherbini SA, Elgebaly HF, Amin $\mathrm{SA}$. Prevalence of multiple organ dysfunction in the pediatric intensive care unit: Pediatric risk of mortality III versus pediatric logistic organ dysfunction scores for mortality prediction. Rev Bras Ter Intensiva. 2017 Apr-Jun; 29(2): 206-12.

5. Giri A, Sharma Y, Sah VK, Niraula N. Multiple organ dysfunction syndrome-clinical profile, associations and outcome in critically III children aged 1 month to 14 years admitted to PICU in Nobel Medical College Teaching Hospital in Biratnagar. BJHS 2019; 4(1)8: 629-33.

6. Karam O, Demaret P, Duhamel A, Shefler A, Spinella PC, Stanworth SJ, et al. Performance of the pediatric logistic organ dysfunction-2 score in critically ill children requiring plasma transfusions. Ann Intensive Care. 2016; 6(1):98.

7. Carcillo JA, Podd B, Aneja R, Weiss SL, Hall MW, Cornell TT, et al. Pathophysiology of pediatric multiple organ dysfunction syndrome. Pediatr Crit Care Med. 2017; 18(3 Suppl 1):S32-S45.

8. Upperman JS, Bucuvalas JC, Williams FN, Cairns BA, Cox CS, Doctor A, et al. Specific etiologies associated with the multiple organ dysfunction syndrome in children: Part 2. Pediatr Crit Care Med. 2017; 18(3 Suppl 1): S58-S66.

9. Wilkinson JD, Pollack MM, Ruttimann UE, Glass NL, Yeh TS. Outcome of pediatric patients with multiple organ system failure. Crit Care Med. 1986; 14(4):2714.

10. Haque A, Siddiqui NR, Jafri SK, Hoda M, Bano S, Mian A. Clinical profiles and outcomes of children admitted to the pediatric intensive care unit from the Emergency Department. J Coll Physicians Surg Pak 2015; 25(4):301-3.

11. Villeneuve A, Joyal JS, Proulx F, Ducruet T, Poitras N, Lacroix J. Multiple organ dysfunction syndrome in critically illchildren: Clinical value of two lists of diagnostic criteria. Ann Intensive Care. 2016; 6:40.

12. Mtaweh H, Kochanek PM, Carcillo JA, Bell MJ, Fink EL. Patterns of multiorgan dysfunction after pediatric drowning. Resuscitation. 2015; 90:91-6. 
13. Watson RS, Crow SS, Hartman ME, Lacroix J, Odetola FO. Epidemiology and outcomes of pediatric multiple organ dysfunction syndrome. Pediatr Crit Care Med. 2017; 18(3):S4-16.

14. Gourd NM, Nikitas N. Multiple organ dysfunction syndrome. J Intensive Care Med. 2019 Aug 27:885066619871452.

15. Haque A, Saleem AF. On admission hypomagnesemia in critically ill children: Risk factors and outcome. Indian J Pediatr. 2009; 76(12):1227-30.
16. Ramzan S, Zaffar J, Mazhar S. Hyponatremia among critically ill children admitted to pediatric intensive care unit (PICU). J Med Physiol Biophys. 2017; 37:359.

17. Ahmed K, Jafr SK, Bhatti F, Rafique A, Haque A. Clinical profile and outcome of children admitted with status epileptics in PICU of a developing country. Pak J Neurological Sci 2013; 8(2):1-6.

18. Volakli E, Sdougka M, Tamiolaki M, Tsonidis C, Reizoglou M, Giala M. Demographic profile and outcome analysis of pediatric intensive care patients. Hippokratia. 2011; 15(4):316-22.

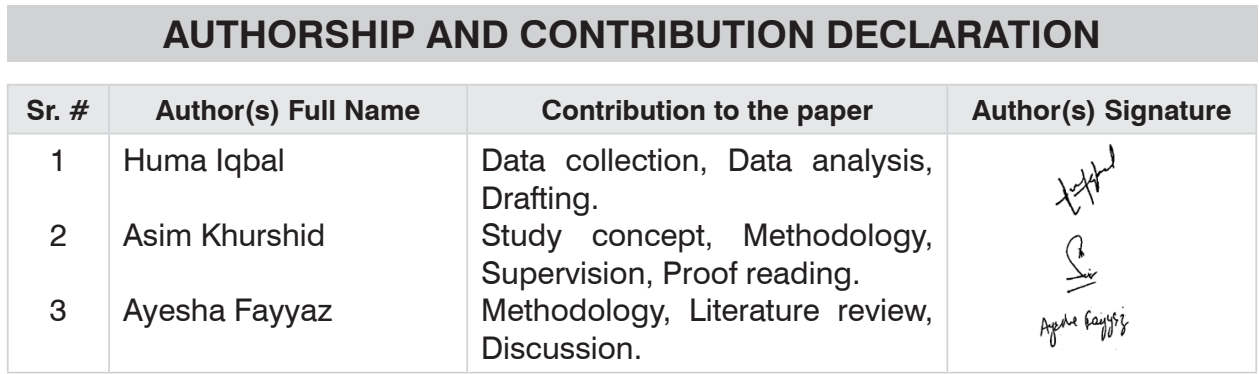

